\title{
CARECER DE DERECHOS: UNA INTRODUCCIÓN A LOS ESTUDIOS TEÓRICOS SOBRE LA APATRIDIA
}

\section{LACK OF RIGHTS: AN INTRODUCTION TO THEORETICAL STUDIES ON STATELESSNESS}

Violeta Alejandra Chávez Bautista'

\begin{abstract}
O bien te dan el certificado del estado (y lo llevas contigo), con lo que adquieres una identidad que durante el curso de tu vida le permite al estado identificarte y seguir tu rastro (dar contigo), o bien vives sin identidad y te condenas a vivir fuera del estado como un animal (los animales no tienen documentos de identidad). No solo no puedes ingresar en el estado sin certificación: para el estado no estás muerto hasta que se certifica tu muerte; y solo puede certificar tu muerte un funcionario que, a su vez, detenta una certificación del estado.
\end{abstract}

Coetze, Diario de un mal año

\begin{abstract}
RESUMEN: Testimoniar la existencia de un individuo es una obligación del Estado, tanto que el acceso a un acta de nacimiento, manifiesto en el derecho a la identidad y el derecho a la nacionalidad, se ha elevado al rango de derecho fundamental. El Estado nunca ha sido neutral, no testimonia sin más, categoriza, segmenta lo existente, colocando a los individuos en una jerarquía que los define como "alguien": persona, menor, ciudadano, etc. El Estado también decide quién es "nadie" y lo clasifica como apátrida, aquel que no es reconocido por ningún Estado como su miembro. Según el ACNUR, durante 2015 se contabilizaron más de tres millones de apátridas en el mundo, sin embargo, se calcula que la cifra es definitivamente mayor y que, eventualmente, éste será un problema tanto geopolítico, en términos de migraciones, supervivencia cultural de Occidente y efectividad de sus Estados, como de fundamentación del Derecho en lo que hace a la definición de sus sujetos y a la legitimidad de sus cánones. El objetivo de este documento es presentar una perspectiva contemporánea de las causas, efectos y tratamiento institucional de la apatridia. Mostrando, a partir de ello, la relevancia de la figura del apátrida para el análisis político internacional actual.
\end{abstract}

PALABRASCLAVE: Apatridia; Estado; causas yefectos; Tratamiento institucional de la apatridia.

ABSTRACT: To testify about the existence of an individual is an obligation of the State, this is true as the access to a birth certificate, shown on the right to identity and the right to nationality, has risen to the rank of Fundamental Right. State has never been neutral, does not testify without more, it categorizes, segmenting the reality, placing individuals in a hierarchy that defines them as "someone": person, child, citizen, etc. The State also decides who is "nobody" and classifies it as a Stateless person, who is

Doctorante en Ciencia Política por la Universidad Nacional Autónoma de México; Maestra en Filosofía por la Universidad Nacional Autónoma de México.violeta.a.chavez@gmail.com 
not recognized by any state as its member. According to UNHCR, in 2015 there were more than three million of Stateless people in the world, however it is estimated that the figure is higher and that eventually this will be a much geopolitical problem, in terms of migration and effectiveness of the State, as substantiation of Law regarding the definition of its subject and the legitimacy of its canons. The purpose of this document is to present the contemporary causes, effects and institutional treatment of Statelessness. This will show the importance of the condition of Statelessness for an international political analysis.

KEY WORDS: Statelessness; State; cause and effect; Institutional treatment of statelessness.

\section{INTRODUCCIÓN}

Según Delgado (2013), el término apatridia apareció por primera vez en el diario francés La Loi en 1918, fue empleado por Charles Claro para sustituir al alemán heimatlos o heimatlosat que se refería a la tierra natal y, jurídicamente, al domicilio, por lo que significaba "sin hogar" o "sin domicilio".

En sentido estricto, tanto para el español como para el francés, un apátrida es una persona sin patria, es decir, sin padre. Es claro que la referencia al pater vincula al concepto con la tradición judeocristiana, lo cual no supondría un defecto si no fuese el caso que, en el mito judeocristiano, la salida del territorio del Padre se describe como una expulsión culposa. El castigo ganado, sea cual fuere su índole, es tan razonable para Occidente que tenemos Derecho, pero la pertinencia de hablar de castigo se quiebra en el caso de la apatridia: ¿qué acto, palabra o pensamiento debe realizarse para no tener derecho a la nacionalidad, al reconocimiento y a la protección de la ley?

La apatridia refiere al Estado y no a la patria. No se trata de la orfandad de los recién nacidos expósitos, abandonados furtivamente en un hospital o en el quicio de alguna puerta, no se trata de la trágica escena en que la vida de un ser humano es dejada al arbitrio de la Fortuna. Se trata de una orfandad aséptica, el apátrida puede ser un adulto, tiene lazos familiares, la gente le conoce por su nombre, quizá hasta su padre biológico le ame, pero no hay un solo Estado en el mundo que lo reconozca como un ser existente.

Dicho lo anterior, podríase interpretar que un apátrida es un sin-Estado. Apólida es el término que empleaban algunos textos jurídicos del siglo pasado en América Latina y que se sigue usando en el italiano, sin-polis. No es la persona sin pater la que interesa, sino la persona en desamparo, sin esfera jurídica, sin inmunidad estatal; de manera tal que la mejor versión del concepto podría ser la inglesa, statelessness.

Así, por el uso corriente que se le da, apatridia es una palabra apropiada para describir la condición de los sin-Estado; mientras que, por el origen etimológico de la palabra, apatridia resulta inaceptable.

Debido a que su uso está ampliamente difundido, sobre todo en los instrumentos jurídicos internacionales y en las investigaciones vinculadas a ellos, la definición de apatridia que empleo en adelante, es la que ofrece la Oficina del Alto Comisionado de Naciones Unidas para los Refugiados (ACNUR): un apátrida es un individuo que no es reconocido como su nacional por ningún Estado. 


\section{LAS CAUSAS DE LA APATRIDIA}

Para abordar las causas de la apatridia sugiero, primero, una clasificación propia que considero útil. Siendo individuos no reconocidos como nacionales por ningún Estado, los apátridas pueden serlo transnacionales, cuando deben atravesar alguna frontera, o locales, cuando no han atravesado fronteras nacionales. Esta simple distinción me parece conveniente porque me ha permitido considerar al menos una causa eficiente del fenómeno de apatridia y de la que más tarde hablaré.

Ya que se ha dicho que la apatridia refiere a la ausencia de vínculo entre un individuo y algún Estado, además de que esa irrelación no es culposa, se entiende mejor la proposición siguiente: la apatridia es un producto del Estado. Por supuesto que se trata de una perspectiva de análisis macro histórico del Estado que no debe considerarse una contribución a los argumentos que proponen la demolición del Estado, ni en sentido liberal ni en cualquier otro. Ciertamente, como el resto de los Órdenes sociopolíticos de los que se ha dotado la humanidad, el Estado desaparecerá, pero no será pronto y, hoy por hoy, no existe otra fuerza aglutinadora ni otro actor que articule con suficiente potencia la defensa de ideales políticos como la igualdad y la libertad; de modo que la intención de observar los efectos perniciosos del Estado, como la apatridia, forma parte de una estrategia de reconducción y re evaluación del mismo.

En términos generales, las causas de la apatridia, que casi siempre son parte de las singularidades estructurales o históricas del Estado, pueden ser las siguientes: 1) conflictos de leyes, 2) sucesión de estados, 3) leyes de matrimonio, 4) prácticas administrativas, 5) discriminación, 6) privación de la nacionalidad y 7) renuncia del individuo a su nacionalidad. Un análisis más profundo muestra que esas causas son:

i. Que la legislación nacional de un Estado entre en conflicto con la de otro, puede dejar a los individuos sin nacionalidad. Tal es el caso de individuos que nacen de padres extranjeros en territorios que sólo otorgan la nacionalidad por ius sanguinis, sin poder acogerse a la nacionalidad de los padres porque en sus países de origen la misma se otorga según ius soli.

ii. La sucesión de Estados también es causa de apatridia para muchas personas, las transferencias de territorios, la unificación de estados, la disolución de un Estado o la separación de una parte del territorio, provocan un vacío institucional que deja sin nacionalidad a los extranjeros, descendientes de extranjeros y recién nacidos.

iii. La falta de equidad de género en las leyes de matrimonio de algunos países promueve la aparición de casos de apatridia, al hacer del derecho a la nacionalidad un derecho propio de los varones y no de las mujeres. Esta minusvaloración de la mujer como sujeto de derecho se manifiesta de diversas maneras: cuando la celebración o disolución del matrimonio afecta a la nacionalidad de la mujer, cuando el cambio de nacionalidad del esposo durante el matrimonio afecta a la nacionalidad de la mujer, cuando la adquisición de la nacionalidad del esposo implica la pérdida de la nacionalidad de la mujer y, en algunos casos, cuando una mujer extranjera no puede adquirir la nacionalidad del esposo pero un hombre extranjero sí puede adquirir la nacionalidad de la esposa. Es así como muchas mujeres, y después también sus hijos, quedan en condiciones de apatridia.

iv. También los asuntos administrativos y procesuales pueden limitar el acceso a la nacionalidad de los individuos mediante gastos excesivos, plazos que no 
pueden ser cumplidos, imposibilidad de aportar documentos requeridos o algo tan simple como inaccesibilidad de los registros civiles, ya sea por la distancia a la que se encuentran, ya sea por el idioma que hablan los funcionarios.

v. La apatridia también ocurre cuando hay revocación automática de la nacionalidad aplicada a individuos naturalizados, comúnmente se trata de personas a las cuales no se les ha notificado que si, por ejemplo, no se presentan a una oficina de manera regular o permanecen fuera del territorio nacional, su nacionalidad está en riesgo de perderse (Unión Interparlamentaria Mundial, ACNUR, 2008).

vi. A pesar de que la discriminación por razones de raza, religión, género y origen nacional o étnico está prohibida de manera transversal en las actuaciones e instrumentos jurídicos de casi todos los estados del mundo, es un hecho que ésta ocurre. Particularmente en el caso de los procesos de desnacionalización que, generalmente, van seguidos de la expulsión de los individuos, el ejemplo más dramático es el del pueblo rohingyá considerado la comunidad de apátridas más grande del mundo, habitantes musulmanes de la frontera entre Birmania y Bangladesh que son víctimas de las políticas antimusulmanas de los budistas de ambos estados, a tal grado que no se les reconoce nacionalidad alguna y son constantemente expulsados de los territorios desde 1978, al menos.

vii. Otra razón por la cual los individuos pueden volverse apátridas corresponde al derecho de los estados para revocar la nacionalidad a los individuos de manera legal. Esto ocurre si la nacionalidad ha sido obtenida de manera fraudulenta, si un naturalizado reside fuera del territorio durante un cierto periodo de tiempo, si el individuo ha faltado a la lealtad con el Estado o ha actuado en contra de sus intereses, o si el individuo ha repudiado al Estado receptor. Esta práctica es más común de lo que se cree y parece estar reforzándose a partir del incremento de la actividad terrorista aislada y suicida; diversos gobiernos, Francia por ejemplo, han decidido retirar la nacionalidad a individuos naturalizados a los que se vincule con la práctica o planificación de actos terroristas.

viii. Por último, quizá la causal más relevante, la no presentación e inscripción de los recién nacidos en el registro civil. Según S. Heap (2009) hay 51 millones de menores al ańo que no se registran en el momento de su nacimiento. Entre los motivos por los que los padres no inscriben al recién nacido está el desconocimiento de la importancia de hacerlo, el coste que supone el trámite en términos de tiempo y dinero, la incertidumbre sobre si el menor sobrevivirá, la inestabilidad política, las barreras jurídicas, sociales y culturales, y el miedo a ser perseguidos por las autoridades. La creación de incentivos para inscribir el nacimiento es uno de los grandes desafíos para cualquier Estado, sin embargo resulta una tarea que parece tener poca importancia en países como, por ejemplo, Zambia, acosada por la pobreza, el VIH y el SIDA, o Nepal, donde las altas tasas de mortalidad infantil no motivan a los padres a correr con los gastos de inscripción.

La declaratoria de apatridia supone una investigación que se limita a los Estados con los cuales una persona goza de un vínculo relevante, ya sea por haber nacido en el territorio, por descendencia, por matrimonio o por residencia habitual. En algunos casos el criterio de relevancia puede limitar el alcance de la investigación a un sólo Estado o a una entidad que no es un Estado. Establecer si un individuo no es considerado como nacional suyo conforme a su legislación, requiere de un análisis de cómo un Estado determinado aplica sus leyes de nacionalidad a un caso individual. 
Por Estado se entiende lo dicho en la Convención sobre los Derechos y los Deberes de los Estados de Montevideo de 1933, artículo 1, según el cual un Estado es una persona unitaria para el Derecho Internacional si reúne los requisitos de poseer una población permanente, un territorio determinado, un gobierno y la capacidad de entrar en relaciones con otros Estados.

Como se puede ver, la condición de apatridia está atada a la voluntad del Estado, es el Estado emisor el que en su acción, mediante leyes diferenciales y actuaciones discriminatorias, u omisión, mediante la baja presencia institucional o su debilidad, el que reduplica la jerarquía social dejando a ciertos individuos en el desamparo; un desamparo que adquiere tintes más dramáticos si el individuo excede los límites territoriales del Estado en el que ha nacido. A esto me he referido con causa eficiente de la apatridia, una situación de discriminación insensible y casi aleatoria que reduce la carga del Estado en términos de garantías jurídicas y de provisión de bienes públicos.

En el caso de la apatridia local resulta mucho más claro que la desigualdad formal ocasionada por la ausencia de reconocimiento del Estado está atada a la condición social pues, para la apatridia local ésta se produce-generalmente-por la dificultad de registrar a los menores más marginados. Entre los marginados, o grupos vulnerables, se incluye a personas indígenas y nómadas, a menores migrantes y refugiados, a niños de la calle, y a los huérfanos, abandonados y separados de sus padres. Mientras que en el caso de las consecuencias de la apatridia transnacional es fácil observar que se trata de problemas asociados al racismo y a la xenofobia.

\section{LOS EFECTOS DE LA APATRIDIA}

Como se ha visto, las causas de la apatridia son diversas, en los peores contextos, los gobiernos despojan a sus ciudadanos de la nacionalidad por motivos políticos, pero en muchos casos simplemente carecen de la capacidad para reconocer a sus ciudadanos de forma oficial y de dispensarles documentos acreditativos.

Entre los prejuicios que provoca la apatridia a los individuos están el problema de probar la nacionalidad para poder acceder a servicios básicos, viajar, casarse, tener hijos y protegerlos de los riesgos del anonimato jurídico y de la trata (BLITZ, 2009).

La apatridia suele impedir que los nin̄os reciban una educación y que sus padres trabajen legalmente; hace que las personas sean vulnerables a la explotación laboral y sexual, la trata, el arresto y la detención arbitrarios, la discriminación y otros abusos; la apatridia es causal para denegar a las familias el acceso a la atención sanitaria y les impide casarse, poseer bienes y abrir cuentas bancarias.

En algunos Estados de la Unión Europea se niega de forma sistemática a muchos apátridas el acceso a los servicios sanitarios y educativos de los que gozan los ciudadanos, como en el caso de los "ciudadanos borrados" de Eslovenia ${ }^{2}$. En Malasia, a niños apátridas

En 1996, el gobierno esloveno literalmente borró el nombre de 18.305 residentes de su registro de ciudadanos. Dichos nombres se incluyeron en un registro de extranjeros que vivían de forma ilegal en Eslovenia y, desde entonces, se les niegan los servicios sociales. Véase: 〈http://www.justiceinitiative.org/ db/resource2?res id=103920>. 
en Selangor y Sabah, con frecuencia se les niega el acceso a la educación básica. En Níger más de cien mil árabes mahamid viven todos los días bajo amenaza de expulsión.

El ACNUR sostiene que los derechos humanos de las personas apátridas, en principio, deben ser respetados en el país de la residencia habitual, mientras las personas apátridas siguen siendo sujetos de extrema indiferencia y de ilimitado castigo sin garantías, lo que incluye la detención. Por supuesto, el hecho de que los derechos humanos sean violados no niega su existencia.

Además de los efectos concretos en la garantía de derechos y el acceso a los servicios, la condición de apatridia logra poner un signo sobre su portador, el de sospechoso. (Los parafros com menos de 4 linhas no son bien vistos)

Al final de la II Guerra Mundial la apatridia fue un asunto en la agenda de la recién creada ONU que, rápidamente, reconoció que la cuestión de la apatridia nace de la relación entre la nacionalidad y el Estado nacional. En 1949 el secretario general de la ONU, Trygve Lie, publicó un estudio sobre la apatridia. Dos de las más importantes observaciones de Lie fueron, primero, que la apatridia es un fenómeno tan viejo como el concepto de nacionalidad y, segundo, que la excepción o exclusión de la nacionalidad es la apatridia y no la extranjería. ${ }^{3}$

El estudio de 1949 de la ONU es de gran importancia por varias razones. Primero, aun cuando el estudio se hizo en términos descriptivos y muy generales, reportó y enunció de manera temprana los efectos que la apatridia tiene en la vida de las personas: escasas expectativas sociales, económicas, educativas, y amplias probabilidades de quedar generacionalmente en desventaja. Unas probabilidades que reflejan, a los ojos de Lie, que la calidad de la organización, de la vida económica y de la esfera legal entera de los individuos residiendo en un país extranjero, depende de su posesión de una nacionalidad específica. ${ }^{4}$

La segunda razón por la cual A Study of Statelessness de la ONU es de vital interés para cualquier estudioso del Estado, los derechos humanos y la globalización, es que la investigación identificó casi de manera definitiva a los tres actores centrales involucrados en el problema de la apatridia, señalando que dicho problema genera dificultades prácticas para los tres, se trata del país de origen, el país de recepción y la persona apátrida misma. Haber identificado a los actores clave constituye un esfuerzo que nadie más ha intentado realizar aparte de la ONU.

Según el estudio de 1949, las dificultades que se presentan en el país de recepción derivan de que el apátrida no encaja en la vida social y administrativa del país al que ha llegado, ni siquiera como extranjero puesto que el estatus que corresponde a los extranjeros es siempre de extranjeros que poseen alguna nacionalidad. De modo que el apátrida es una figura anómala que no recibe la asistencia consular de ningún país en caso de requerirla.

3 En esto coinciden el informe de la ONU, A Study of Statelessness, y Hannah Arendt, Los orígenes del totalitarismo: la apatridia no es una simple variante de la extranjería.

4 A ello debe agregarse, para quien argumente que hemos entrado a una era post-nacional, que es característico y persistente que la mayor parte de los apátridas pertenezcan a grupos culturales minoritarios, como afirma K. Staples en Retheorising Statelessness. Por el momento no contamos con estudios de caso específicos que den cuenta de esta circunstancia más que aquellos a los que refiere la propia Kelly Staples de manera tangencial en la primera parte de Retheorising Statelessness. 
Para las autoridades administrativas del país receptor el problema tiene que ver con el hecho de que los oficiales de la administración rara vez poseen sensibilidad humanitaria para tratar con los apátridas, esto produce que el apátrida se vea forzado a emplear métodos no legales para ganarse el favor de dichos oficiales, lo cual redunda en una afectación a la sanidad de la administración pública local. Más aún, dado que ninguna nación les asiste, los apátridas sufren fácilmente de condicionalidades onerosas a cambio de los servicios administrativos, lo que suele generar una tensión amplia entre los nacionales y los apátridas (UN, 1949: 7-8).

Entre las dificultades para los países de origen se encuentra el hecho de que, cuando el apátrida está en posibilidad de ser un refugiado político, suele preservar un gran resentimiento con el país de origen y, dado que alberga de forma intensa la posibilidad y el deseo de volver, el apátrida puede tornarse un agente de mala propaganda o una peligrosa fuente, activa, ideológica o económica, de atentados contra el régimen de su propio país (UN, 1949: 8-9).

Sobre el individuo apátrida, el informe de Lie indica que se enfrenta a dificultades derivadas de que la ausencia de nacionalidad coloca a las personas en una posición anormal e inferior respecto de los nacionales, reduciendo su valor social y destruyendo su autoconfianza (UN, 1949: 9-10). En el caso de que el apátrida haya sido expulsado de su país de origen, se ve obligado a entrar en otro país de forma fraudulenta lo que lo hace permanecer oculto y a vivir bajo la amenaza de ser descubierto, arrestado y sentenciado.

Si el apátrida es aceptado para su reasentamiento, el proceso migratorio incluye, siempre, permisos de corta o mediana duración que deben renovarse constantemente y que pueden ser denegados en cada oportunidad. Esta situación, desde la perspectiva de la persona en condiciones de apatridia, es similar a la de aquel que se encuentra bajo constante vigilancia policial y cuya precariedad dificulta el reasentamiento con posibilidades de éxito.

Las condiciones de vida de un apátrida admitido como trabajador son significativa y particularmente desfavorables, su presencia es tolerada e incluso requerida cuando la producción y el crecimiento nacional son tan elevados que se necesita de un incremento significativo en la fuerza de trabajo, pero una vez que el desempleo se incrementa o reaparece, los apátridas son los primeros en sufrir las consecuencias, su situación es más crítica que la de otros extranjeros debido a que ningún país en el mundo está dispuesto a recibirles.

El apátrida vive bajo los criterios administrativos y leyes del país receptor y, obviando el hecho de que todos los criterios y leyes han sido diseñados para personas que poseen nacionalidad, encuentra siempre dificultades para colmar tales requerimientos. Esto produce una condición de desventaja que suele retardar o imposibilitar su reasentamiento y asimilación.

En sus relaciones con las autoridades del país de recepción, los apátridas son tratados más como alguien que debe ser vigilado y no como alguien cuyos derechos deben ser respetados. La inferioridad de la posición legal de los apátridas se refleja en su posición social y hace de ellos el blanco de la desconfianza y la sospecha en los lugares a los que van.

En la tabla que se presenta a continuación, puede observarse una exposición gráfica de los actores y problemas que ocasiona la apatridia según el estudio de 1949 de UN. 
Tabla 1. Apatridia: actores y su problemas según A Study of Statelessness.

\begin{tabular}{|c|c|c|}
\hline ACTOR & \multicolumn{2}{|r|}{ PROBLEMAS } \\
\hline \multirow{8}{*}{$\begin{array}{c}\text { Individuo } \\
\text { en } \\
\text { condición } \\
\text { de } \\
\text { apatridia }\end{array}$} & \multicolumn{2}{|r|}{ Bajas expectativas sociales, económicas y educativas } \\
\hline & \multicolumn{2}{|r|}{ Bajo valor social } \\
\hline & \multicolumn{2}{|r|}{ Destrucción de su autoconfianza } \\
\hline & \multicolumn{2}{|r|}{ Vigilancia constante por parte de las autoridades locales } \\
\hline & \multicolumn{2}{|c|}{ Caso de expulsión: obligado a realizar actos ilícitos para ingresar a otro país, vida bajo amenaza de ser capturado y procesado } \\
\hline & \multirow{2}{*}{\multicolumn{2}{|c|}{$\begin{array}{l}\text { Caso de reasentamiento: renovación de los correspondientes permisos temporales que se interpreta como vigilancia constante } \\
\text { Caso de trabajador: cuando la producción nacional baja el individuo es discriminado y/o expulsado }\end{array}$}} \\
\hline & & \\
\hline & \multicolumn{2}{|r|}{ Administrativamente: dificultades para cumplir con los requisitos documentales burocráticos } \\
\hline \multirow{5}{*}{ Estado } & \multirow[b]{2}{*}{ Origen } & \begin{tabular}{|c|} 
Seguridad nacional \\
\end{tabular} \\
\hline & & $\begin{array}{c}\text { Tratándose de un caso de expulsión política, el apátrida es un agente de mala propaganda y fuente de } \\
\text { atentados para la desestabilización de los gobiernos, un enemigo potencial }\end{array}$ \\
\hline & \multirow{3}{*}{ Receptor } & El apátrida amenaza la estabilidad institucional y es riesgo de corrupción \\
\hline & & $\begin{array}{c}\text { Anomalía administrativa, el apátrida no encaja ni como extranjero, lo que provoca malos tratos por parte de } \\
\text { los burócratas y cargos onerosos para realizar trámites. En consecuencia el apátrida accede a realizar actos } \\
\text { ilegales para conseguir favores administrativos. }\end{array}$ \\
\hline & & Fuente de corrupción que afecta la calidad de la administración pública \\
\hline
\end{tabular}

Fuente: Elaboración propia.

Como se puede ver en la tabla, los problemas que los estados tienen con la apatridia son cuestiones de seguridad nacional para el Estado de origen y cuestiones de estabilidad institucional y corrupción para el Estado receptor.

En lo que hace a la seguridad nacional, el documento parece prefigurar la caracterización de los individuos que representan amenazas a la seguridad nacional en los actuales documentos de seguridad nacional de algunos países, tanto como la actuación no oficial pero consuetudinaria de los oficiales de seguridad respecto de individuos que, habiendo vivido muchos años en el extranjero, regresan a sus países.

Se trata de problemas que recién han empezado a abordarse y a profundizarse bajo la etiqueta de estudios de contraterrorismo y que resultan de gran relevancia en el mundo contemporáneo, naturalmente las aseveraciones de la investigación de la ONU se quedan cortas en comparación con lo que actualmente se estudia. ${ }^{5}$

Sobre la inestabilidad institucional y el fomento a la corrupción que promueve la presencia de los apátridas en el país receptor, el documento de Lie parece sugerir una causa falsa. La ausencia de protocolos procedimentales claros y unificados, de capacitación del personal y de inclusión de la figura de apátrida, es lo que incentiva conflictos administrativos. Es claro, para los estudiosos de la responsabilidad pública, que la corrupción al interior de un Estado tiene causales mucho más poderosas que la existencia de los apátridas y que, en cambio, la apatridia producida por ausencia de servicios de registro civil, sí que es promovida por la debilidad institucional de los estados.

Respecto de los efectos que la condición de apatridia tiene en la vida de los individuos, el documento de la ONU señala diversas limitantes que se podrían englobar en el ámbito de lo social y de la psicología. Dado que éstas son las condiciones en las que se suele poner atención, no resulta extraño que la mayor parte de los pocos estudios sobre apatridia que podemos encontrar, se hayan realizado desde la perspectiva sociológica.

5 Para ampliar este punto véase el sitio web Global Terrorism Database (GTD) del Institute for Economics \& Peace en «economicsandpeace.org/research/iep-indices-data/global-terrorism-index» 
Seguridad nacional, inestabilidad institucional y desventaja social son las áreas de problematicidad que hacen del estudio de la apatridia un estudio relevante. La situación no es extraña si se le observa en términos de crecimiento y desarrollo económico, o de consolidación de las instituciones. Los estados débiles, al tener un bajo nivel de efectividad, absorben anomalías sin que ello implique un grave impacto; mientras que los estados consolidados, por su parte, al tener un alto grado de efectividad y una alta regulación de los procesos, sufren los efectos de cada anomalía que encuentran apenas se les presenta.

Para los apátridas, la International Detention Coalition IDC señala que cualquier procedimiento se les complica debido a que no pueden probar documentalmente su nombre, país de origen o fecha de nacimiento; esto es peor si se trata de migrantes que cruzan fronteras pues su situación los hace:

1. Ser más susceptibles a la detención.

2. Ser más vulnerables a no recibir asistencia legal ni consular.

3. Tener un conocimiento muy restringido acerca de sus posibilidades dentro del país.

4. Tener dificultades mayores para el acceso a la asistencia de intérpretes y de traductores.

Sobre el internamiento de los apátridas en campos, se sabe que estos lugares vulneran los derechos humanos, lastiman la salud y el bienestar, y causan sufrimiento innecesario.

En el caso específico de México, nuestro Estado prefiere siempre los derechos humanos de sus nacionales que los de otras personas. No existe equilibrio entre las actividades de promoción de los derechos humanos realizadas para la protección de los mexicanos en el exterior, en comparación con los esfuerzos para la de los derechos de los migrantes en México, no existen tribunales especializados en materia migratoria y no existe asistencia judicial especial gratuita para migrantes en condiciones de vulnerabilidad, como los niños, niñas y adolescentes no acompańados (SIN FRONTERAS, 2005).

La misma Ley General de Población mexicana establece disposiciones discriminatorias en contra de los y las migrantes irregulares para la exigencia de sus derechos. Las oficinas del Registro Civil presentan problemas para otorgar los derechos a la identidad y a la nacionalidad, y los jueces u oficiales del Registro Civil muchas veces no celebraran ningún acto en el que intervenga un extranjero que no pueda acreditar su legal estancia en el país y con ello se niega el registro a nin̄os y niñas mexicanos con padres extranjeros sin documentos (SIN FRONTERAS, 2005).

La afectación e impacto que la condición de apatridia sobre la vida de los individuos puede observarse con gran nitidez en los casos concretos, quizá por eso la mayor parte de la investigación sobre apatridia que se ha hecho hasta el momento está conformada por estudios de caso.

Por citar sólo algunos ejemplos, refiero a lo sucedido en Australia en 2004, cuando la Corte Suprema respaldó la práctica del Gobierno australiano de detener por tiempo indeterminado a solicitantes de asilo cuyas peticiones son denegadas, el fallo del que hablo se refería a dos solicitantes: el palestino apátrida Ahmed al-Kateb y el iraquí Abbas al Khafaji, que ni habían logrado obtener visas, ni podían ser retornados a su país o a un tercer país pues sus vidas corrían peligro (ZAYAS, 2005). 


\section{EL TRATAMIENTO INSTITUCIONAL DE LA APATRIDIA}

Las migraciones masivas ocasionadas por conflictos armados y la situación de las personas forzadas a migrar, fueron consideradas un problema estatal de dimensiones internacionales durante el periodo que va del final de la I Guerra Mundial al final de la II Guerra Mundial. En 1946 se fundó la Organización Internacional de los Refugiados que ofrecía protección política a las personas de su interés y se crearon pasaportes para apátridas (NANSEN et al, passim).

En 1950 se fundó el ACNUR y en 1954 se realizó la Convención sobre el Estatuto de los Apátridas. Un organismo y un instrumento internacional que aún están vigentes. Sobre las características políticas que les dan forma cabe recalcar lo siguiente.

Primero, que fue en los Estados originarios y más antiguos donde ocurrieron los desplazamientos masivos de los que se desprende la legislación y consideración internacional contemporánea de la figura de refugiado y, más tarde, la de apátrida. Las razones de tal avance legislativo son, considero:

1. Entre los Estados más antiguos, al menos de forma tentativa, las fronteras quedaron establecidas desde el tratado de Westfalia de 1648, lo que implica que los Estados ya estaban definidos y suficientemente reconocidos como tales en el ámbito internacional, por lo que poseían todas las características de personalidad jurídica, necesarias y suficientes, como para firmar acuerdos internacionales.

2. En términos de legitimidad de la ley, los individuos concretos sobre cuya situación se legislaba eran europeos.

3. Las formas de organización internacional modernas no limitadas a los procesos mercantiles y el establecimiento de los regímenes internacionales tienen una mayor experiencia y, por tanto, estabilidad, entre dichos Estados.

Segundo, que las características propias del elemento militar y de la guerra entre Estados tienen un impacto impensado en términos macrohistóricos sobre la población civil. No estoy diciendo con esto que todos los apátridas transnacionales son producidos exclusiva o directamente por la guerra o la pobreza, actualmente también la crisis ambiental expulsa a los individuos de los lugares en los que suelen habitar.

Tercero, que así como el Estado fue una construcción que se expandió a la periferia de Occidente, así mismo lo son las figuras de refugiado y apátrida ínsitas en el Estado, lo cual implica, para efectos del Estado, unas formaciones específicas que no siguen el supuesto canon del Estado Occidental y, respecto de la apatridia, que los criterios para la declaración de apatridia no son exactos fuera de los Estados occidentales.

Cuarto, que la primera aparición de los apátridas en el escenario y agenda pública ocurre en el ámbito internacional, su existencia y condición se palpa solamente cuando los individuos empiezan a cruzar fronteras, lo cual no significa que no hayan existido ya apátridas locales, es decir, individuos no reconocidos por sus estados debido a fallos, ausencia o ineficiencia de los sistemas locales de registro civil. El cruce de fronteras es el hecho que descubre la intensidad de la desprotección en el que un individuo queda si no hay un Estado que dé fe de su existencia como persona; fuera de su comunidad habitual siempre podrá ser visto como un extranjero en grado superlativo. ${ }^{6}$

$6 \quad$ Debido a la gravedad extrema de sus consecuencias, en esta investigación se hace un mayor énfasis en la apatridia ocasionada o evidenciada por el cruce de fronteras estatales que en la apatridia promovida por la ineficacia institucional. 
Así, las herramientas que los estados poseen para enfrentar el incremento de los casos de apatridia o para reducir su incidencia, tiene que ver con, al menos, dos ejes, con la formulación o adhesión a instrumentos jurídicos, y con el funcionamiento efectivo de sus instituciones.

En lo que hace a los instrumentos jurídicos, entre los intentos reducir la vulnerabilidad de las mujeres a quedar en condiciones de apatridia, Naciones Unidas ha adoptado y promovido la Convención sobre la Nacionalidad de la Mujer Casada en 1957 y la Convención sobre la Eliminación de Todas las Formas de Discriminación contra la Mujer de 1979.

En lo relativo a la dimensión institucional, la importancia del derecho a la identidad, no solamente en su dimensión administrativa, sino de contenido jurídico social, se reconoció hasta el siglo XX, cuando se observó que el registro de los nacimientos sirve para reducir o eliminar las fronteras entre los círculos más marginados de la población puesto que se observa que la ausencia de documento de identidad hace que las personas se tornen invisibles para el Estado.

Tal situación limita las posibilidades de que el Estado actúe como garante de los derechos inherentes a los ciudadanos; impide el acceso a servicios de salud, bienestar y educación; y puede encadenarse o propiciar la vulneración de otros derechos, por ejemplo del derecho a la integridad en los casos en que ocurre el tráfico de menores o la desaparición forzada de personas. El registro civil es indispensable para la existencia de bases de datos y de sistemas estadísticos suficientemente confiables como para utilizarse a la manera de herramienta en la planificación e implementación de las políticas de desarrollo.

La Convención sobre el Estatuto de los Apátridas de 1954 es el primer tratado internacional cuyo objetivo específico es la regulación de los tratos para las personas en condición de apatridia. El artículo 1(1) de la Convención establece que "A los efectos de la presente Convención, el término "apátrida" designará a una persona que no es considerada como nacional suyo por ningún Estado, conforme a su legislación" (ACNUR, 2012a, p. 2).

El objetivo de la Convención de 1954, como se indica en la misma, es garantizar que los apátridas disfruten del ejercicio más amplio posible de sus derechos humanos bajo la consideración expresa de que el reconocimiento de alguna, cualquier, nacionalidad es preferible al reconocimiento de un individuo como apátrida.

Para el ACNUR la repatriación voluntaria es la solución preferida a los problemas que suscita la condición de desplazado, refugiado y apátrida. La repatriación implica el compromiso del país de origen para la protección y reintegración de los ciudadanos a sus comunidades, pero para que ello suceda se deben haber producido cambios positivos, es decir, deben haber desaparecido las causas que impulsaron la huida de los individuos.

Si la repatriación voluntaria no es posible, se busca la integración local en que el refugiado obtendrá, gradualmente, derechos equivalentes a los derechos de los ciudadanos locales hasta llegar a los derechos de residencia permanentes. Esta es una condición que siempre implica la ciudadanización o la naturalización y que requiere que el refugiado se adapte a la sociedad de acogida, tanto como que los anfitriones reciban y satisfagan las necesidades de los refugiados. Para los Estados parte de los diversos 
instrumentos sobre refugiados y apátridas, la integración debe incluir la regularización legal, orientación social, la enseñanza de la lengua y la capacitación laboral.

Si la repatriación voluntaria y la integración local no pueden realizarse, entonces se busca el reasentamiento en un tercer país, un procedimiento que se realiza según un mecanismo específico de cuotas anuales en que las naciones signatarias ofertan plazas de reasentamiento por vía del ACNUR. A lo largo de los ańos, se observa, las plazas ofertadas para el reasentamiento no han aumentado de forma significativa, se calcula que son unas 80,000 en total en todo el mundo. Estados Unidos y Canadá son los estados que actualmente reciben el mayor número de reasentados en sus territorios.

En todos los casos de solución duradera, la regla que priva es la de negativa al refoulement, la expulsión o devolución del asilado a fronteras o territorios en que su vida o libertad peligran por causa de su raza, religión, nacionalidad, grupo social u opiniones políticas. Para los Estados parte del conjunto de tratados y convenios sobre refugiados y apátridas, la expulsión de un refugiado sólo es admisible en el caso de que existan motivos de seguridad nacional u orden público. Siempre se debe garantizar la posibilidad de que el asilado acceda a la apelación por medio de un tribunal local y el retorno del asilado resulta aceptable solamente hasta que un tercer Estado le asegure el asilo.

En el caso específico de la apatridia, el ACNUR prevé que la solución vendrá de la construcción de legislaciones supranacionales que promuevan que los países otorguen - de manera sencilla - documentos y, después de un proceso específico, la nacionalidad, ciudadanía o naturalización a los individuos que la requieran, con el objetivo implícito de que la existencia de tales individuos vuelva a ser reconocida y tutelada por alguien.

Importa decir que, a pesar de la existencia de leyes supranacionales como el Estatuto de los Apátridas, no existe ningún tribunal o mecanismo claro y específico que sancione el incumplimiento de los tratados sobre apatridia. Más aún, dado que la adhesión a los tratados es voluntaria, cada Estado parte puede interponer reservas, salvedades y excepciones, en la firma de las leyes.

El BID, por su parte, asegura que el área de intervención denominada Desarrollo de Políticas Nacionales de Identidad se ha vuelto central, por lo que busca mejorar la capacidad de los gobiernos para diseñar e implementar políticas de identidad legal, e incrementar el conocimiento y apoyo para políticas nacionales de identidad basadas en los derechos. Para ello, tanto el BID como el CCR fondean estudios que permitan identificar el estado de las políticas de registro civil e identidad legal; planes y diseño de políticas de registro civil e identidad legal focalizadas en niňos, y asistencia técnica para alinear regulaciones nacionales con convenciones internacionales. Además intervienen técnicamente mediante discusiones sobre tendencias internacionales en necesidades emergentes relacionadas con los registros civiles; intercambio de conocimientos para compartir mejores prácticas y lecciones aprendidas en registro civil e identidad legal, incluyendo la forma en que éstas aplican a niños, mujeres, poblaciones indígenas y otras poblaciones vulnerables; e instrucción para los responsables de capacitar a funcionarios de los registros en materia de estándares internacionales.

En el caso específico de México no existe una agencia especializada en apatridia. Sin embargo la Comisión Mexicana de Ayuda a Refugiados (COMAR), publica algunas cifras de manera poco formal. Las siguientes gráficas muestran las solicitudes de refugio que la COMAR procesó durante el año 2015, mismas que no son definitivas según la institución. 
Como se puede observar en las siguientes gráficas, el porcentaje de refugiados que México reconoció en 2015 es de $23.9 \%$ para la categoría "personas" y de $9.1 \%$ para la categoría de niños y niñas no acompańados. ${ }^{7}$

Gráfica 1: Personas que fueron reconocidas como refugiados por México durante 2015.

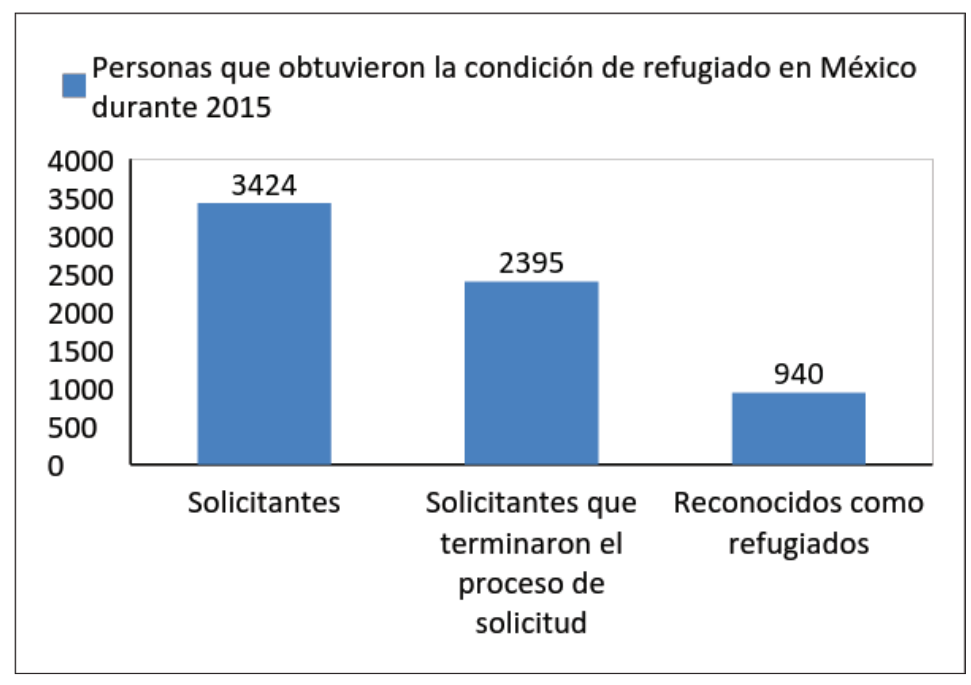

Fuente: elaboración propia a partir de datos de la COMAR (2016).

Gráfica 2: Niños y niñas no acompañados que fueron reconocidos como refugiados por México durante 2015.

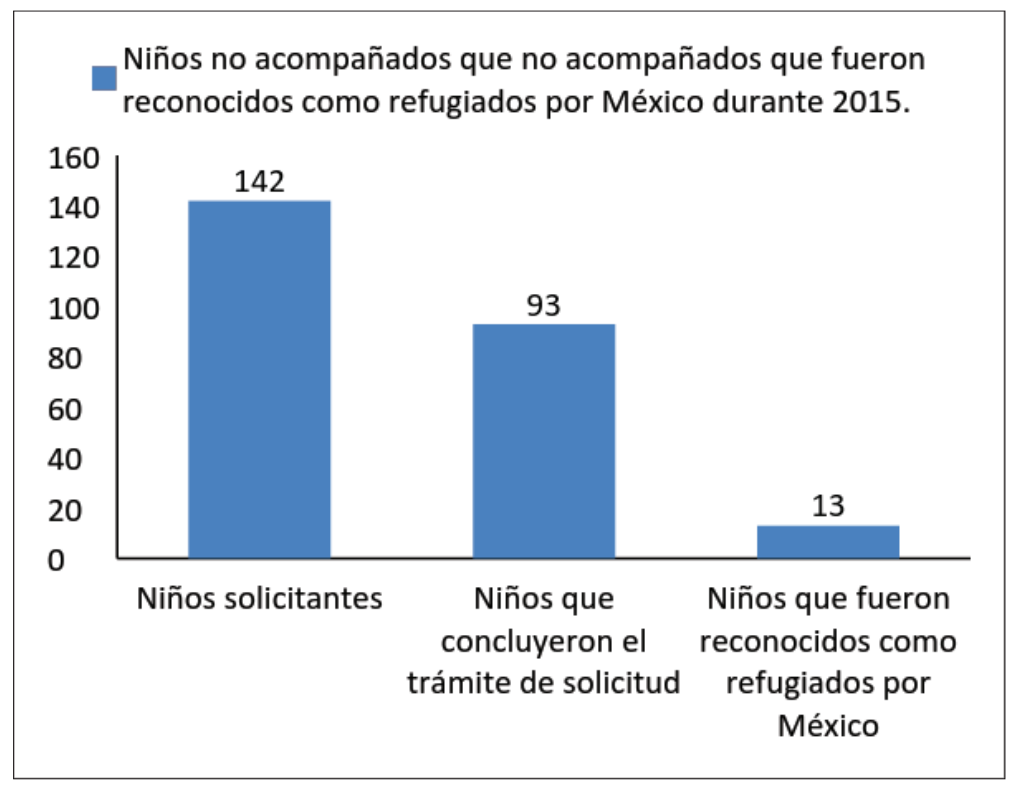

Fuente: elaboración propia a partir de datos de la COMAR (2016).

$7 \quad$ No existe aclaración en el sitio web acerca de si entre las 3424 personas solicitantes ya figuran los 142 niños y niñas no acompañados que solicitaron ser reconocidos como refugiados en México durante 2015. 


\section{CONCLUSIONES:LA RELEVANCIA DE LA FIGURA DEL APÁTRIDA PARA EL ANÁLISIS POLIITICO INTERNACIONAL}

El estado de la apatridia en el mundo pasa por sus cifras, mismas que presento a continuación y que han sido extraídas de diversos informes anuales del ACNUR. ${ }^{8}$ Observar de qué regiones del mundo, incluso de qué países, provienen las grandes masas de desplazados puede darnos una idea mucho más certera de las razones sociales de las migraciones humanas irregulares. ${ }^{9}$

El último reporte del ACNUR, 2015, muestra el incremento de cifras como población total de interés del ACNUR, apátridas totales y apátridas en África. Como se ve en la tabla siguiente, a pesar de los problemas ocasionados por la desnacionalización de personas de origen haitiano en República Dominicana, el ACNUR señala que el número de apátridas en América y Latina y el Caribe ha descendido.

Tabla 2: Tendencias globales 2015.

\begin{tabular}{c|c|c|c|r|r}
\hline Área de asilo & $\begin{array}{c}\text { Total refugiados yersonas } \\
\text { en situación similar a la de } \\
\text { los refugiados }\end{array}$ & $\begin{array}{c}\text { Desplazados internos } \\
\text { y en situación similar } \\
\text { asistidos por ACNUR }\end{array}$ & $\begin{array}{c}\text { Personas bajo } \\
\text { el mandato de } \\
\text { apatridia de ACNUR }\end{array}$ & Varios & $\begin{array}{c}\text { Población } \\
\text { total de interés } \\
\text { ACNUR }\end{array}$ \\
\hline África & $4,811,365$ & $11,197,751$ & $1,021,440$ & 521,910 & $17,755,821$ \\
\hline Asia & $8,694,562$ & $17,265,028$ & $1,942,856$ & 246,303 & $29,704,046$ \\
\hline Europa & $1,820,424$ & $1,918,326$ & 586,848 & 77,414 & $5,487,592$ \\
\hline $\begin{array}{c}\text { América } \\
\text { Latina y } \\
\text { Caribe }\end{array}$ & 337,698 & $7,113,067$ & 136,585 & 25,113 & $7,659,144$ \\
\hline Norteamérica & 409,090 & - & - & & - \\
\hline Oceanía & 48,288 & - & - & & - \\
\hline Total & $16,121,427$ & $37,494,172$ & $3,687,729$ & 870,740 & $63,912,738$ \\
\hline
\end{tabular}

Fuente: Elaboración propia con datos del ACNUR.

En términos generales, la tendencia incremental en el número de desplazados a nivel global es imposible de precisar, ya sea debido a los problemas metodológicos de la medición, ya sea debido a la intermitencia con que las intervenciones armadas se hacen presentes en algunos países.

Las estadísticas que ha generado el ACNUR podrían estar indicando que el aumento o decrecimiento en el número de refugiados, desplazados y apátridas, suele deberse a conflictos armados, ${ }^{10}$ inestabilidad socioeconómica de los países y desastres naturales. Sin embargo, la causa principal de la migración vinculada a la apatridia sigue siendo la violencia: a mayor violencia, conflictividad e inestabilidad, mayor volumen y mayor frecuencia de las migraciones masivas. Lo que podemos observar en la gráfica son momentos de algidez de la violencia armada y de la inestabilidad socioeconómica, medidos a través de la cantidad de apátridas que tales circunstancias produjeron.

\footnotetext{
$8 \quad$ Para éste y todos los casos aquí referidos, se han consultado los documentos disponibles en el sitio web del ACNUR, en: <http://www.acnur.org/t3/recursos/estadisticas/>

9 Por migración irregular se entiende migración indocumentada.

10 Así lo interpreta el ACNUR, incluso ha titulado el informe de 2013: Los costes de la guerra.
} 


\section{Gráfica 3: Personas en condición de apatridia atendidas por el ACNUR por año durante el periodo 2004-2013.}

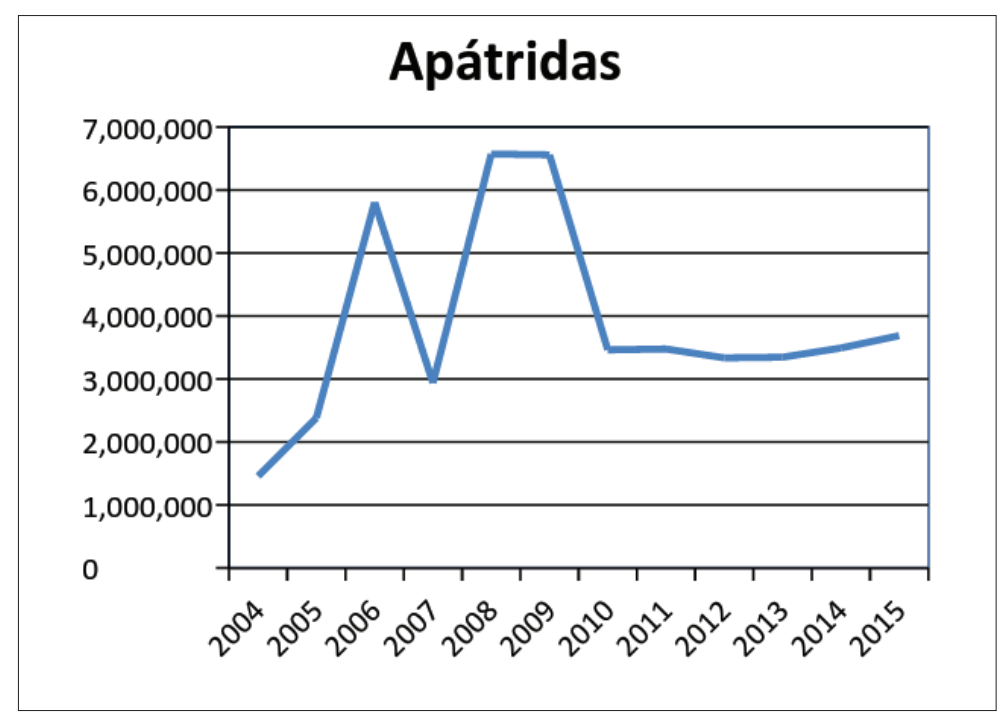

Fuente: Elaboración propia con datos del ACNUR.

Una vez abordada la apatridia como un problema internacional, su definición según la norma de la ONU, sus cifras y su vínculo con los conflictos armados, queda claro que la apatridia transnacional es la primera en aparecer en la escena internacional y en su agenda. Por tanto, y a pesar de las deficiencias que su tratamiento y medición tiene, es justamente la apatridia transnacional la que recibe mayor atención en términos de análisis, obviándose el hecho de que es posible ser apátrida sin haber cruzado ninguna frontera nacional.

La tensión entre inclusión y exclusión que forma parte de todas las historias de la humanidad, se ha visto reforzada por la tendencia expansionista de la globalización (S. CASTLES, 1997), la propensión a abarcar toda área geográfica y grupo humano, tanto como a establecer diferencias entre los grupos humanos, ha hecho emerger un nuevo nivel en la posibilidad de que algunas personas se conviertan en miembros de pleno derecho mientras otras quedarán marginadas de la esfera global.

En términos de acceso diferenciado a los derechos, la expansión de la globalización implica, tanto para los apátridas locales como para los transnacionales, la restricción o acceso limitado al trabajo, a la oportunidad de ganarse la vida mediante un trabajo libremente escogido o aceptado, lo que supone que ya antes ha sido limitado el acceso a la orientación y formación técnico profesional, programas, normas y técnicas encaminadas a conseguir un desarrollo económico, social y cultural constante y la ocupación plena y productiva.

La fuerza de trabajo contenida en los cuerpos de los apátridas es orientada hacia el trabajo informal y semi esclavo en el que no se cumplen las condiciones mínimas de salario equitativo e igual por trabajo de igual valor, en particular para las mujeres; las condiciones de existencia dignas para el trabajador y su familia; la seguridad e higiene del entorno laboral; la igual oportunidad para todos de ser promovidos; el descanso, el disfrute del tiempo libre, la limitación razonable de las horas de trabajo y las vacaciones periódicas pagadas, así como la remuneración de los días festivos; elementos todos del derecho laboral más básico. 
El derecho a la salud, a la certeza jurídica de la propia vivienda, a la educación y todos los derechos sociales que conforman la estructura, compensatoria o no, que se considera razonable para que los individuos puedan desarrollarse y alcanzar, gracias a sus esfuerzos y talentos, la mayor de sus potencialidades, están vedados o casi vedados para los apátridas. Si esto ya era grave e injusto, la globalización lo exacerba por medio de su selectividad económica.

La globalización se vincula con el incremento de la desigualdad entre individuos y entre naciones a través de la migración internacional, ésta se debe no sólo a la conflictividad sociopolítica o la pauperización del mercado laboral, sino al deterioro del medio ambiente. La deforestación, la desertización, la disminución de la fertilidad de los suelos, las sequías, las inundaciones, las presiones sobre recursos y ecosistemas que generan competencia económica, conflicto político y guerras, obligan al desplazamiento masivo de personas.

En términos de derecho, el rasgo más significativo de la globalización, dice Ferrajoli (2006), es el vacío de derecho público con el que opera. Mientras en su dimensión económica desnacionaliza procesos, tráficos y mercancías mediante la constante firma de acuerdos y tratados comerciales suscritos entre particulares, en el espacio de la política se diseñan y renacionalizan políticas migratorias excluyentes que contravienen, o son paralelas, a tratados internacionales suscritos por algunos Estados.

El temor acerca del decaimiento de la cultura occidental no es infundado, el National Intelligence Council (NIC, 2012), oficina de análisis y anticipación geopolítica y económica de la Central Intelligence Agency (CIA), tiene sus pronósticos sobre mega-tendencias para el ańo 2030, y avisa del declive de Occidente frente a las naciones emergentes.

Según el NIC (2012), la inestabilidad demográfica se tensará y ello tendrá un serio impacto en los procesos y características de la migración transfronteriza. Aun así, la migración interna ocurrirá a niveles más altos que la internacional, impulsada por la rápida urbanización, factores ambientales y por el impacto del cambio climático. Es probable que afecte a África y Asia mucho más que a otros continentes debido a la dependencia de la agricultura y a una mayor susceptibilidad a fenómenos meteorológicos extremos.

Sobre los efectos que la migración internacional promueve, Castles (1997) se pronuncia en el mismo sentido. En los países de emigración ocurre la disolución de las estructuras económicas y sociales tradicionales. En los países de inmigración el asentamiento de los inmigrantes puede llegar a transformar la economía nacional y a las ciudades, promoviendo la reflexión sobre valores sociales y culturales locales. Es indudable, dice Castles, que esto sucederá en los países recientemente industrializados de Asia, América Latina y África.

En teoría, las mayores tasas de migración producirían una mayor rentabilidad para el desarrollo mundial. A decir del NIC (2012), el Banco Mundial estima que un aumento de 3 puntos porcentuales en el número de migrantes en 2025, lo que daría lugar a un aumento del 0,6 por ciento en los ingresos globales. Esto es, los migrantes producirán una ganancia de \$368 millones de dólares para los países en desarrollo, de suerte que la migración será vista como una estrategia económica por muchos países. ¿Significa eso que la distancia entre la residencia permanente, a la que la mayoría de los migrantes pueden calificar, y la ciudadanía, inalcanzable para muchos, se podría comenzar a acortar?, ¿para quiénes? 
La posible migración de los países musulmanes con altas tasas de natalidad, podría crear nuevas fricciones políticas y sociales. La Fundación Pew, referida por el NIC (2012), pronostica que la población musulmana de Europa se duplicará desde el 4,1\% de la población total de Europa en 2012, al 8\% en 2030.

Además, el NIC (2012), considera que los flujos de millones de personas de los países en desarrollo más pobres a los países de ingresos medios o países desarrollados, crea el potencial para abusos enormes de los derechos humanos y la explotación. Las comunidades de inmigrantes abren vías para el aumento de la actividad delictiva, como el contrabando de drogas. El rápido crecimiento de los desequilibrios de género y edad entre los países desarrollados y en desarrollo, también aumentan las posibilidades de mayor tráfico de seres humanos.

El reporte 2015 de ESADEgeo, también anuncia que las migraciones crecerán y que los migrantes musulmanes pueden cambiar la faz de Occidente en lo que hace a la cultura, particularmente en lo que hace a los valores de la democracia. Los cambios económicos pueden tener consecuencias en el ámbito internacional pues, preocupados por la crisis del estado de bienestar y constreñidos por los problemas presupuestarios los países desarrollados podrían reducir su nivel de compromiso, continuarán reduciendo el gasto militar, su ayuda al desarrollo y su aportación a la financiación de organismos multilaterales, a largo plazo este escenario podría poner en cuestión la preeminencia de los valores occidentales en la esfera internacional.

La siguiente gráfica muestra cómo las migraciones internacionales se han focalizado en el corazón de Occidente, lo cual explica las altas probabilidades de la modificación de los valores propios.

Gráfica 4: Países de acogida para cerca de la mitad de los migrantes mundiales totales durante 2013.

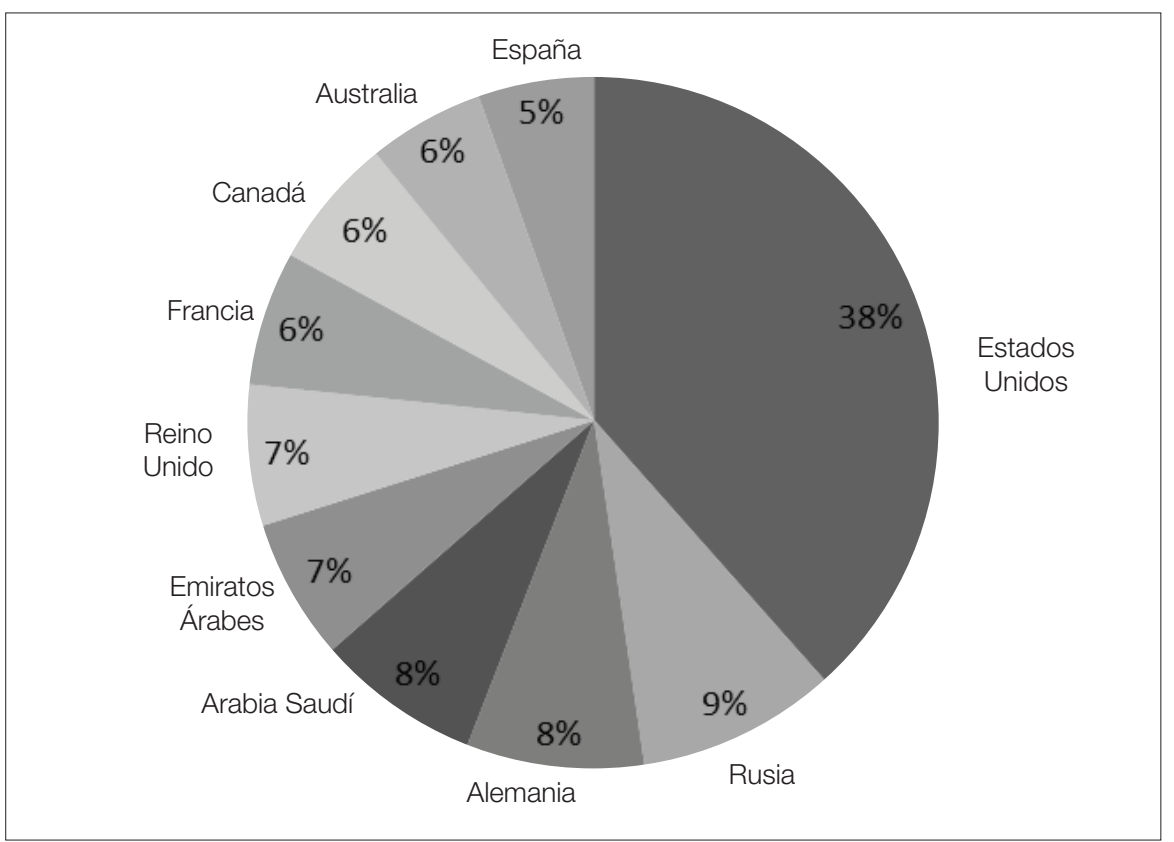

Fuente: elaboración propia con datos del reporte DAES \& OCDE, 2013. 
ESADEgeo (2015) señala que las tendencias para 2030 en términos de gobernanza global ${ }^{11}$ muestran intereses divergentes y un número creciente de actores, esto hará que sea más difícil lograr el consenso para la reforma de las instituciones multilaterales. Como el Consejo de Seguridad de las Naciones Unidas; en consecuencia para 2030 los instrumentos de gobierno serán menos globales.

Se puede decir que la debilidad de los estados se ha vuelto el origen del mal del mundo, un mal que se instancia en singularidades y rostros con características sociales, económicas o culturales específicas.

Los otros que vienen sin papeles son posibles culpables de terrorismo, de la diseminación de enfermedades, sospechosos de ser infieles a los principios civilizatorios que han llevado a Occidente a la construcción de los regímenes internacionales humanitarios y de protección de derechos humanos.

La debilidad estatal culposa, el mal del sistema internacional debe ser reconocido, estudiado y, no se sabe cómo, resuelto porque, como señala F. Fukuyama en La construcción del Estado (2004, p. 140):

Los Estados débiles o fracasados conculcan los derechos humanos, provocan desastres humanitarios, causan oleadas masivas de inmigración y atacan a sus vecinos. Desde el 11-S también ha quedado claro que protegen a terroristas internacionales que pueden ocasionar daños significativos a Estados Unidos y otros países desarrollados. A lo largo del periodo que se extiende desde la caída del muro de Berlín, en 1989, hasta el 11-S, en 2001, la inmensa mayoría de las crisis internacionales han girado en torno a Estados débiles o fracasados. Entre ellos se encuentran Somalia, Haití, Camboya, Bosnia, Kosovo, Ruanda, Liberia, Sierra Leona, el Congo y Timor Oriental.

En el marco de la globalización no basta con señalar que el Estado ha de fortalecerse institucionalmente para evitar las conflagraciones internas y la amenaza externa, no bastan el diseño o la ingeniería institucional. Llevando el razonamiento a otro nivel, debe considerarse la revisión crítica de los elementos que históricamente conforman al Estado y que, habiendo estado presentes desde sus orígenes, hoy podrían lucir como condiciones necesarias para la existencia del Estado y ser, sin embargo, perfectamente contingentes.

Reconocer la contingencia de los elementos del Estado, me parece, permitiría repensar con mayor justeza las condiciones y circunstancias que guardan los estados en desarrollo, y dejar de observar sus características propias como degeneraciones o malformaciones respecto del ideal de Estado. Los estados en desarrollo no son copias frágiles, fallidas o débiles de los estados desarrollados; estudiarlos en su especificidad puede ayudar a una comprensión más cabal de sus problemáticas tanto como al diseño de estrategias más viables y factibles para la resolución de sus conflictos.

11 Por gobernanza global se entiende la construcción de consensos sobre la elección óptima de políticas y su coordinación para tratar cuestiones globales tales como migraciones, cambio climático, comercio internacional o seguridad alimentaria. El empleo de esta estrategia ayuda a evitar que los países o las entidades privadas tomen decisiones unilaterales que afecten a terceros, distorsionen los mercados, generen presiones especulativas, desarticulen el medio ambiente de la agricultura, etc., por tanto sus principios son la participación, la transparencia y la rendición de cuentas (FAO, 2013). 
En resumen, en términos macro es claro que conforme la modernidad se expande, difundiendo a escala global la economía y mercaderías, la sociedad occidental se ve permeada por las alteridades culturales, que el Estado cuyo plan programático moderno incluyó a la igualdad y la reducción u ocultamiento de la violencia ha producido la apatridia y que la apatridia manifiesta la exclusión institucional de los individuos que parece subrayar la necesidad del fortalecimiento del derecho internacional de los derechos humanos. Por otra parte, en términos de historia de vida, la condición de apatridia es el desamparo más dramático que puede acaecer a un ser humano, el de ser nadie. 


\section{REFERENCIAS}

ACNUR. Directrices sobre la apatridia No. 1. La definición de "Apatridia" en el artículo 1 (1) de la Convención sobre el Estatuto de los Apátridas de 1954. 2012. Disponible en: <http://www.refworld.org/docid/4fc5cela2.html>. Recuperado el 1 de septiembre de 2015.

Tendencias globales 2013. El coste humano de la guerra. 2014. Disponible en: <http://www.acnur.org/t3/fileadmin/scripts/doc.php?file=t3/fileadmin/Documentos/ Publicaciones/2014/9562>. Recuperado el 10 de octubre de 2015.

Tendencias globales. Desplazamiento forzado en 2015. Forzados a huir. 2016. Disponible en: <http://www.acnur.org/fileadmin/scripts/doc.php?file=fileadmin/ Documentos/Publicaciones/2016/10627>. Recuperado el 2 de septiembre de 2016.

ARENDT, Hannah. Los orígenes del totalitarismo. (Traducción de G. Solana). México: Taurus, 2004.

BLITZ, Brad. Campańas de reivindicación y desarrollo de políticas. En Revista Migraciones Forzadas. N. 32, junio 2009. España: Centro de Estudios sobre Refugiados de la Universidad de Alicante, University of Oxford. pp. 25-27. Disponible en: <www. migracionesforzadas.org>. Recuperado el 2 de marzo de 2016.

CASTLES, Stephen. Globalización y migración: algunas contradicciones urgentes. Discurso pronunciado ante el Consejo Intergubernamental del MOST-UNESCO. 1997. Disponible en: 〈http://www.ub.edu/prometheus21/articulos/nautas/18.pdf〉. Recuperado el 8 de septiembre de 2016.

COETZE, J. M.. Diario de un mal año. (Trad. de J. Fibila). Barcelona: Random House, 2007.

DELGADO, Pedro Pablo. Apátridas, refugiados y migrantes. El derecho a la libre circulación. Perú: Fondo de Cultura Económica, 2013.

ESADEgeo. The Global Context: How Politics, Investment, and Institutions Impact European Businesses. España: ESADEgeo, 2015.

FAO. Panorama de la seguridad alimentaria y nutricional en México 2012. México: FAO, 2013. Disponible en: ‘www.fao.org/publications〉. Recuperado el 3 de septiembre de 2016.

FERRAJOLI, Luigi. Derechos y garantías. La ley del más débil. (Cuarta edición). (Traducción de P. Andrés \& A. Greppi). Madrid: Trotta, 2006.

FUKUYAMA, F.. La construcción del Estado. Hacia un Nuevo orden mundial en el siglo XXI. (Traducción de M. Alonso). Barcelona: B, 2004.

HEAP, Simon, et al.. Campaña de Inscripción Universal de Nacimientos. En Revista Migraciones Forzadas. N. 32, junio 2009. España: Centro de Estudios sobre Refugiados de la Universidad de Alicante, University of Oxford. Pp. 20-22, 2009. Disponible en: <www.migracionesforzadas.org>. Recuperado el 20 de diciembre de 2013.

INSTITUTE FOR ECONOMICS \& PEACE. Global Terrorism Database (GTD). Disponible en: <economicsandpeace.org/research/iep-indices-data/global-terrorism-index>. Recuperado el 20 de enero de 2016. 
NIC. Global trends 2030: Alternative Worlds. USA: NIC, 2012. Diponible en: ‘https://globaltrends2030.files.wordpress.com/2012/11/global-trends-2030-november2012.pdf>. Recuperado el 15 de julio de 2015.

OEA. Convención sobre los Derechos y los Deberes de los Estados, Montevideo, 1933.

ONU. Convención sobre el Estatuto de los Apátridas, 1954.

. Convención sobre la Nacionalidad de la Mujer Casada, 1957.

Convención sobre la Eliminación de Todas las Formas de Discriminación contra la Mujer, 1979.

SIN FRONTERAS. Informe alternativo. Aplicación de la Convención Internacional sobre la Protección de Todos los Trabajadores Migratorios y sus Familiares. México. México: Sin fronteras, 2005. Disponible en: <http://www.sinfronteras.org.mx/attachments/article/74/INFORME_ALTERNATIVO.pdf>. Recuperado el 16 de junio de 2015.

STAPLES, Kelly. Retheorising Statelessness. A background Theory of Membership in World Politics. Great Britain: Edinburgh University Press, 2012.

UNIÓN INTERPARLAMENTARIA MUNDIAL DEL ACNUR. Nacionalidad y apatridia. Manual para parlamentarios. Costa Rica: Master Litho, 2008. Disponible en: <http:// www.acnur.org/t3/fileadmin/Documentos/BDL/2011/7108.pdf?view=1〉. Recuperado el 14 de mayo de 2015.

UNITED NATIONS. A Study of Statelessness. 1949. Discponible en: <http://www.refworld.org/docid/3ae68c2d0.html>. Recuperado el 12 de febrero de 2014.

ZAYAS, Alfred de. Derechos humanos y detención por tiempo indeterminado. Revista Internacional de la Cruz Roja. 2005. Diponible en: <https://www.icrc.org/spa/resources/documents/article/review/6e3m3d.htm>. Recuperado el 19 de mayo de 2016. 